\title{
CONFIGURACIONES Y AUTOREPRESENTACIONES DIGITALES DE GÉNERO Y MASCULINIDAD EN TINDER
}

\author{
CONFIGURATIONS AND DIGITAL SELF-REPRESENTATIONS \\ OF GENDER AND MASCULINITY ON TINDER
}

\author{
Lénica Rodríguez Cruz Manjarrez \\ Universidad Autónoma de Barcelona, España \\ (D) https://orcid.org/0000-0003-2219-4128

\section{Pilar Albertín Carbó} \\ Universidad Autónoma de Barcelona / Universidad de Girona, España \\ (iD https://orcid.org/0000-0001-6995-509X
}

Autor para correspondencia: Lénica Rodríguez Cruz Manjarrez, email: lenica.rodriguez@e-campus.uab.cat

\section{Resumen}

Tinder es un espacio digital con contenido y categorías predefinidas para su uso e interacción. Desde la presentación de un perfil heterosexual, el espacio coloca al sistema sexo -género binario como punto de partida en la producción y reproducción del discurso de la masculinidad, que de manera hegemónica y dominante se construye en las sociedades occidentales. Ese modelo se funda en el privilegio y el éxito del estereotipo de hombre blanco y heterosexual, que goza de un amplio espectro de movilidad económica y social en la esfera pública contemporánea. El presente artículo es el resultado y análisis de una muestra de perfiles de hombres heterosexuales que se presentan en Tinder, en Barcelona, España. Para ello conjugamos elementos de la etnografia digital, los estudios visuales, psicosociales, y del discurso multimodal. Observamos que, desde el avatar digital de presentación, los hombres heterosexuales muestran cómo la representación de esa preferencia sexual es performada y autorepresentada, produciendo un contenido estrechamente relacionado con discursos y configuraciones de género y masculinidad; ampliamente reavivados, reafirmados y producidos en la comunicación mediática y digital de esta época.

Palabras clave: género, masculinidad, heterosexualidad, autorepresentaciones digitales, Tinder.

\begin{abstract}
Tinder is a digital space with predefined content and categories for use and interaction. In the presentation of heterosexual profile, the space gives to the binary sex-gender system a central place in the production and reproduction of the discourse of masculinity, which is constructed in a hegemonic and dominant way in Western societies. This model is founded on the privilege and success of the stereotype of the heterosexual white male, who
\end{abstract}

Global Media Journal México, 18(34), 229-251, enero - junio 2021. 
has who has broad economic and social mobility in the contemporary public sphere. This article is the result and analysis of a sample of heterosexual men profiles on Tinder, in Barcelona, Spain. For this we combine elements of digital ethnography, visual, psychosocial studies, and multimodal discourse. In the digital avatar of presentation, heterosexual men show how the representation of that sexual preference is performed and selfrepresented, producing content closely related to discourses and configurations of gender and masculinity, widely revived, reaffirmed and produced in media and digital communication in this time.

Keywords: gender, masculinity, heterosexuality, digital self-representations, Tinder.

Recibido: 16/04/2021

Aceptado: 08/06/2021

\section{Introducción}

La tecnología ha inundado nuestra vida cotidiana. Transitamos en una aparente era de la comunicación y cercanía tecnologizada, donde ya no es ajeno que los dispositivos electrónicos y el internet son herramientas de comunicación humana sin barreras de tiempo y espacio. Además de ser un campo abierto y de acceso a la información, el internet es un espacio donde se produce una gama de interacciones de todo tipo, incluidas aquellas de las que ni siquiera tenemos un alcance claro. Lo que hoy denominamos ciberespacio (Ardèvol y Muntañola, 2004; Castells, 2010; Hine, 2014) es un campo de acción social para miles de seres humanos, ya sea por trabajo, estudio, o bien sólo por ocio y búsqueda, donde la realidad en lo virtual juega un papel difícilmente reemplazable en la vida de las sociedades contemporáneas (Barrionuevo y Torrano, 2018; Haraway, 1991), suscritas a un modelo económico capitalista y socialmente moderno (Bauman, 2005; Giddens, 1998; Torrano, 2019).

Las redes sociales digitales (RSD) producen un contexto de realidad virtual basado en dos formas: online (conexión por dentro) y offline (conexión por fuera) (Hine, 2014). En ambas, la característica principal reside en que las personas se mantienen vinculadas con una red de contactos que pueden conocer físicamente o no, con los que se interactúa desde la red de modo online y a su vez, al salir temporalmente de la red, en un modo offline, también podrían realizar interacciones motivadas por su conexión virtual. En ambas formas, la realidad virtual como contexto social puede ser un objeto de análisis.

En el presente estudio nos concentramos en el modo online porque las redes sociales digitales asociadas a la tecnología de los dispositivos portátiles e internet (tales como computadoras, tabletas, teléfonos celulares) están diseñadas para usarse y moverse junto con el sujeto sin la determinación de tener un lugar fijo, de tal forma que 
las personas, influidas por ello, muestran sus perfiles de identidad digital muy cercanos a lo que hacen, piensan o dicen en su vida cotidiana offline.

Las RSD son variadas y tienen usos distintos, produciendo múltiples formas de comunicación, presentación y representación de las personas para la interacción social. Seleccionamos una RSD y aplicación digital usada para el encuentro de personas y/o pareja, denominada Tinder, la cual, se caracteriza principalmente por ofrecer al sujeto la posibilidad de encontrar una persona con la cual se pueda establecer un contacto físico posterior, ya sea para conocerla y/o concretar una relación; además que esta red está específicamente diseñada para usarse de acuerdo con la preferencia sexual de sus usuarios.

Dentro de la RSD Tinder, cualquier persona define su propio perfil o avatar digital presentado (ADP), el cual funciona como puente de conexión y representación para quien a su vez haga uso de dicha red, emergiendo así una serie de acciones e interacciones que colocan al sujeto en un espacio virtual y digital (Pink et al., 2019). Esta acción, por un lado le permite expresar abiertamente aquello que desea mostrar o no de sí mismo (Ranzini y Lutz, 2017; Serrano-Puche, 2015); pero también, de manera implícita, mostrar una serie de presupuestos y criterios delineados por la cultura de origen, en dos sentidos: la cultura cotidiana de la que forma parte (Miller, 1995; Poster, 2002) y el actual mundo moderno, en donde sin duda, las concepciones sobre el género y la sexualidad están presentes (Butler, 1988, 2007), así como los aspectos normativos asociados a ello.
Por tanto, el presente estudio se basa en analizar lo arriba mencionado a través de Tinder que, además de ser una aplicación digital para conocer personas y acordar citas online, también tiene un componente importante como red social, al estar vinculada con el perfil de la persona en Facebook o Instagram, las cuales son las redes sociales digitales ampliamente usadas en el mundo por lo que produce un criterio de confiabilidad, pues aparentemente garantiza que las citas se ejecuten con personas que se han mostrado desde lo digital, con probables elementos de quiénes son y sus intereses; una representación de sí mismas para posibles encuentros en el entorno offline.

Cabe señalar que lo que aquí se presenta es parte de un estudio más amplio, sobre las representaciones de género en el uso de las RSD, sin embargo, para el presente artículo presentamos específicamente los resultados del análisis de los ADP de usuarios hombres, con perfil heterosexual, que se presentan en Tinder, en Barcelona, España; para lo que utilizamos elementos de la etnografía digital, los estudios visuales y psicosociales (Hine, 2004; Pink, 2010, Pink et al., 2019; Reavey y Johnson, 2008; Reavey, 2012), así como del análisis del discurso multimodal (Forceville, 2011; Kress, 2010; Niklander et al., 2015; O'Halloran, 2012; Van Dijk, 2019; Van Leeuwen y Jewitt, 2004).

Aunque en la última década se ha desarrollado un número considerable de investigaciones sobre las páginas web de citas en el contexto español (Caballero y Herrero-Jiménez, 2017; Calvo González et al, 2020; Espinar-Ruiz y Ocampo, 2017a, 2017b; Martínez-Lirola, 2012), la 
propuesta actual es hacerlo en las aplicaciones digitales y las RSD con perspectiva de género para el análisis de las masculinidades (Casimiro, 2014). En ese sentido, el presente artículo pretende constituirse en un aporte, tanto teórico como empírico, para el campo de estudio.

Por consecuencia, los objetivos que se plantean son los siguientes: 1. Conocer cómo los hombres autorepresentan su masculinidad en la RSD Tinder y qué características son emergentes en relación con ella. 2. Visualizar si hay una masculinidad dominante dentro del repertorio de masculinidades que se presentan. 3. Comprender cómo esta representación se relaciona con el sistema sexo-género binario, especialmente cómo define la representación tipológica de mujer y rasgos de feminidad que se conjuga con la masculinidad dominante representada en Tinder. 4. Identificar algunos efectos de Tinder en la representación masculina a partir de los avatares digitales presentados.

\section{Marco teórico}

\section{La normatividad de género dominante}

en la cultura occidental: La masculinidad

y la feminidad como representaciones

binarias de sexo-género

La normatividad de género dominante consiste en una cultura basada en el sistema sexo-género binario (heterosexual), es decir, o se es hombre o se es mujer, con unos estereotipos prefijados y unos roles sociales esperados desde la cultura occidental. La idea social de "ser hombre" o "ser mujer", se define por esos estereotipos de masculinidad y feminidad y tiene que ver con lo que las autoras West y Zimmerman (2009) denominan "doing gender". Se trata de un orden, de una estructuración social que configura el mundo y la forma de ser y estar en él de las personas. Aparece en los esquemas de percepción, en los valores que se toman como modelos y referencias, en los estilos de vida, etc; y especialmente, la manera de comprender las prácticas sociales en la relación de pareja, enamoramiento y relaciones afectivo-sexuales. Dicho orden establece la creencia de los opuestos complementarios: masculino y femenino, que da ámbitos sociales de comportamiento e ideas de cómo deben, bajo una marcada diferencia, "ser" y "actuar" tanto mujeres como hombres. Esto es, una fábrica social de ideas que refuerzan un enfoque binario, que por definición negará otras expresiones e ideas respecto al género (Bard y Magallanes, 2018).

Por su parte, Butler (2007) nos explica cómo se performan estas categorías binarias (de "ser hombre o mujer") a través de las actividades cotidianas, no tanto a partir de una "obligación" que impone y prescribe objetivamente el deber ser, sino en especialmente a través de una normativa que normaliza y "naturaliza" lo que se inscribe en los cuerpos de las personas; que seduce, que imprime el deseo individual por "querer ser" y/o "conseguir ser" un hombre (o una mujer) dentro de las definiciones pre-dadas y hegemónicas.

Las categorías creadas en torno a los géneros son vistas como producto de la naturaleza y no como 
producto de la creación humana-social, eso hace difícil la transformación y promueve que la persona se acepte dentro de esa categoría y se asuma como tal. Estas categorías de hombre y mujer, con su respectivo estereotipo de masculinidad/feminidad, aparecen en las sociedades occidentales como procesos de socialización que preservan la estructura heteropatriarcal de las mismas (Rubin, 1986). De esta manera, las normativas de género tradicionales han socializado a las mujeres en la feminidad, situando como eje central de sus vidas el amor y el cuidado de las personas. También han potenciado valores como la empatía, la comprensión, la tolerancia y el perdón, que, si bien son valores fundamentales para la existencia y mantenimiento de la vida, pueden tener efectos negativos en cuanto a que se convierten en el objeto central y el sentido de su vida, es decir, el someterse a ser en función del otro (Butler, 2001). Ambas categorías masculinidad/feminidad- se sustentan y se autoalimentan para mantener el entramado social de la heterosexualidad.

La masculinidad socializa a los hombres, haciéndolos más autónomos e independientes, racionales, con capacidad de decisión, fuerza, resistencia, protectores de la familia, proveedores, etc. Los diversos estudios sobre la masculinidad (Connell, 2003, 2012; Connell y Messerschmidt, 2005; Gilmore, 1994; Kimmel, 1996, 2007) hablan sobre diferentes formas de ésta a través de la historia en las distintas sociedades, pero distinguen una que aparece de manera constante y ciertamente se define por ser dominante en la dinámica social; a esta masculinidad se le ha conceptualizado como hegemónica, dominante y tradicional. Connell (2003), basa el desarrollo de la masculinidad en cuatro dinámicas: hegemonía, sumisión, complicidad y marginalidad. La hegemonía se vincularía al grupo de masculinidades que se encuentran en una posición superior dentro del género. Se naturalizará su existencia y se usará como guía para saber cómo deben comportarse "los hombres", especialmente a partir de una posición de mando frente a las mujeres y reclamando su autoridad acorde con esto. También existe una subordinación entre los propios actores masculinos, la más extendida es la que se genera entre los hombres heterosexuales y los homosexuales. Otro grupo situado dentro de esta hegemonía son los hombres conocidos como "cómplices", quienes se aprovechan de las situaciones o sistemas creados a partir del contexto hegemónico. Si los sistemas de género los unimos también al de clase y raza, obtenemos nuevas distinciones y jerarquizaciones entre masculinidades, donde la hegemonía se sustenta por hombres blancos con poder económico.

Por su parte, Kimmel (en Carabí y Armengol, 2008) explica que los hombres construyen estrategias de autoafirmación de la masculinidad y que pasan necesariamente por establecer conexión con la masculinidad hegemónica y dominante, la cual tiene como principio caracterizar a los hombres como seguros, fuertes, estables y en constante verificación de su masculinidad. Dichas estrategias se basan en tres formas de manifestación en el ser y hacer de los hombres: el autocontrol, la huida y la exclusión. La primera tendrá que ver con el cuerpo, al controlarlo 
y hacerlo lucir fuerte. La segunda establece las características de relación con la mujer, en particular la visión que se tiene de ésta cuando es esposa dominante- de la cual es mejor huir. La tercera establece la tendencia de los hombres de saberse favorecido en la sociedad -desigual-, por lo que para mantener ese desbalance aparece la exclusión de las mujeres y otros hombres, que es la base del sexismo, la homofobia y otras formas de marginación y segregación.

Con lo anterior, Kimmel (Carabi y Armengol, 2008) hará referencia a que la masculinidad es un problema serio, con un modelo desarrollado y basado en el hombre blanco y heterosexual. Además, como explica Bonino (2002), la masculinidad es también entendida como una estructura simbólica, compuesta por una serie de mitos, creencias y significados sobre qué es ser hombre y cómo tiene que comportarse. Esta estructura preexiste al sujeto y permite construir una identidad y autorepresentación que opera a nivel subjetivo y corporal que es implantada desde lo emocional-vincular, a través de un proceso continuo de socialización.

Se pueden identificar cuatro matrices configuradas por creencias mantenidas por el sujeto hombre y que lo sujetan a la masculinidad hegemónica (Bonino, 2002), las cuales funcionan como mecanismos para evitar el conflicto con "lo que debe hacer para ser hombre" desde la masculinidad hegemónica. Estas cuatro matrices de creencias son: a) la autosuficiencia prestigiosa, la cual consiste en ser autónomo, independiente, consiguiendo logros, poder, autorealización; b) la belicosidad heroica, que destaca la cualidad de luchador, héroe, o bien como deportista competente y resistente; c) el respeto al valor de la jerarquía, a través de ocupar un reconocido lugar en la estructura jerárquica masculina, o en la institución, o en lugares de poder y decisión; d) la superioridad sobre las mujeres o los varones feminizados y su diferenciación.

Bonino (2002) además propone que para trabajar en el desmontaje de esta masculinidad dominante se requiere deshacer las múltiples estructuraciones sociales e individuales que la conforman y mantienen, superando resistencias materiales y emocionales que comporta este proceso.

\section{Autorepresentación digital de la masculinidad}

Connell (2003) también refiere que los sujetos se han conformado mediante una visión del ser hombre, que de forma hegemónica se reitera ampliamente en la mass media y la cultura, y pareciera que los hombres, más allá de sus condiciones individuales de identidad, optan por acercarse a ese modelo arquetípicamente, usando máscaras (Gil Calvo, 2005), que les permiten la acción de representar el género, en este caso, activar el performance digital. La representación digital que aparece en las RSD nos permite ver cómo las personas, hombres y mujeres, en la aceptación del binarismo heterosexual, hacen de su ADP algún tipo de resonancia con el modelo masculino o femenino dominante e interactúan bajo su efecto.

En las RSD hay una continua autorepresentación del género y su sexualidad 
asignada, con intersecciones de otras variables como la edad, los cánones de belleza, la raza o etnia y la clase social (Platero, 2012). Estamos hablando de una visualidad en la contemporaneidad (Bard y Magallanes, 2021) que implica la circulación de imágenes y video en las RSD que produce catálogos en línea como parte de nuevo orden de valor económico.

En este mismo sentido, Illouz (2009) muestra cómo la sociedad capitalista y de consumo logra entrar en el plano emocional-relacional, especialmente en las relaciones amorosas y afectivosexuales, incorporando en estas, la idea de amor romántico y el consumo de ciertos objetos: el poder económico como gran valor ligado a la autorepresentación y a las identidades de los sujetos, la mercantilización de los cuerpos, la inscripción de ciertos contextos y escenarios como ideales para las relaciones amorosas y/o sexuales. Lo que se pone en juego en los espacios sociales de las RDS, de especial importancia para las ciencias sociales, son los deseos $\mathrm{y}$ afectos de las personas, que son la base del uso de esas plataformas (Bard y Magallanes, 2021).

Con relación a la sexualidad, Osborne (1995) cuestiona cómo se ha construido históricamente la desigualdad entre los sexos y la conducta sexual, de manera que la sexualidad masculina hegemónica se manifiesta bajo formas violentas, centradas en los genitales y el acto sexual, con ausencia de emocionalidad y de alguna actitud igualitaria hacia las mujeres, así como hacia otros hombres que no llevan como estandarte alguna forma de masculinidad dominante. El determinismo biológico es una de las explicaciones ofrecidas para entender la división de las prácticas relacionadas con la sexualidad y el deseo, la cual subyace y justifica la opresión de las mujeres.

Aunque hoy día estos estereotipos, roles y sexualidad están cambiando sus significados (Halberstam, 2012), los medios de autorepresentación social de la sexualidad continúan ligados a patrones conservadores de la conducta permisiva hacia los hombres y restringida para las mujeres. No obstante, la cultura heterosexual masculina va cambiando con el tiempo y se acerca a nuevos modelos de masculinidad que los vuelven más alternativos, con posibilidades de cambiar las restringidas formas binarias del género.

Ahora bien, el problema es cómo pensamos el género en nuestra sociedad, cómo circulan los productos -cuerpos- en el mundo, comprando, intercambiando sexo, etc., en donde las RSD tienen un papel importante con la creación de imágenes estereotipadas donde el régimen heterosexual se reaviva nuevamente. Hablamos aquí de una economía del deseo (Segato, 2003), así como de una intervención tecnológica de afectación masiva (Torrano, 2019), que reitera regresar a las visiones conservadoras y dominantes de la masculinidad, lo que trae consigo que los hombres, en su propia representación y la representación que tienen de las mujeres, se muevan en un margen muy reducido de acción. De manera pragmática, éstos toman el modelo hegemónico sin amplia reflexión de toda acción, física, verbal o simbólica de los estándares masculinos; un modelo que sin duda produce desigualdad y violencia de género (Bonino, 2002). 


\section{Método}

Esta investigación utiliza elementos de la etnografía digital, los estudios visuales y psicosociales (Hine, 2004; Pink, 2010, Pink et al., 2019; Reavey y Johnson, 2008; Reavey, 2012), así como del análisis del discurso multimodal (Forceville, 2011; Kress, 2010; Niklander et al., 2015; O’Halloran, 2012; Van Dijk, 2019; Van Leeuwen, 2008; Van Leeuwen y Jewitt, 2004). Analizamos algunas ADP de hombres en Tinder a partir de las ideas de la semiótica social multimodal, que afirma que la comunicación se produce de múltiples formas y modos. Es decir que, al emitir un mensaje con distintos recursos comunicativos (imagen-texto) se crean significados que darán cuenta de una representación potencialmente comunicativa, denotativa (descriptiva) y connotativa (interpretativa) de significación, en correspondencia a la cultura y la vida cotidiana donde tenga lugar.

Cada modalidad semiótica (textual, auditiva, visual, etc.) tendrá significaciones diferentes para comunicar algo específico, pero cuando se enlazan se convierten en un conjunto semiótico complejo de prácticas y recursos que forman parte de la cultura para dar significados. Cabe aclarar que no se trata de una conjunción simple de las modalidades semióticas, más bien de un análisis que implica identificar la significación de aspectos relevantes de las relaciones sociales de quienes intervienen o participan en la comunicación.

Concretamente se analizaron algunas ADP de representaciones masculinas en Tinder, como espacio de producción, distribución y recepción del material semiótico, de donde obtuvimos un conjunto aleatorio de $n=120$ hombres en Barcelona, que manifestaban en su ADP buscar relaciones específicamente heterosexuales; pues cabe aclarar que, en esa RSD, los usuarios pueden presentar sus perfiles desde una preferencia sexual diferente.

Lo primero fue obtener la muestra no probabilística, tomando los perfiles que aparecieran en la aplicación digital Tinder, a través de su función de búsqueda de hombres heterosexuales en un radio no mayor a 25 kilómetros del campus universitario de la Universidad Autónoma de Barcelona. Se usaron sólo dos criterios de inclusión para obtener los ADP masculinos heterosexuales: que estuvieran en un rango de edad entre 25 y 46 años y que su ADP tuviera fotografía y texto de presentación. Para recolectar la muestra se usaron tres perfiles de mujeres heterosexuales en el mismo rango de edad, donde cada uno obtenía perfiles en el radio. La conexión no fue simultánea, cada perfil usó días diferidos para que la muestra fuese amplia y plural.

Sin establecer un número previo, se tuvo en cuenta la posible saturación (Martínez-Salgado, 2012) para el ejercicio multimodal. La muestra final para el presente estudio quedó en $n=120$ perfiles. Ésta se compone por un $40 \%$ de ADP de hombres entre los 41 y 46 años; un $41 \%$ entre los 36 y 40 años; un $14 \%$ entre los 30 y 35 años y un 5\% entre los 25 y 29 años. Los resultados han sido obtenidos a través de los modos imagen y texto de presentación; es decir, la descripción -denotativa- de los ADP, para transversalmente, hacer un análisis multimodal desde el engranaje teórico arriba presentado. 


\section{Resultados y discusión}

\section{De los ADP en lo textual}

Para la revisión del texto de presentación de los ADP, agrupamos tres categorías a través de los enunciados escritos por los usuarios: la descripción de símismos, lo que buscan en ese espacio y lo que ofrecen.

Conforme a lo anterior, en la primera agrupación de texto se encuentra la descripción sobre las características de sí mismo. Este conjunto es amplio, $78 \%$ de la muestra lo tiene, ya que la aplicación digital propone una descripción personal de inicio; en ésta pueden definirse desde diversos aspectos de orden personal como actitudes y valores, formación académica, actividad laboral, hobbies o actividades cotidianas. Este grupo alude a los valores $\mathrm{y}$ actitudes que los describen personalmente, y el uso recurrente de adjetivos como ser serio, honesto, divertido, amigable, romántico, amoroso, viajero, aventurero, trabajador, positivo, entre otros. También citan los hobbies y actividades cotidianas, entre las cuales destacan, los deportes, deportes extremos, actividades en viajes y salidas a clubes nocturnos. Hay también mención de actividades como tocar algún instrumento musical o acudir a actividades artístico-culturales. En cuanto a la descripción por formación académica o actividad laboral algunos citan datos específicos de profesión o lugar laboral. No se identificaron citaciones explícitas sobre creencias religiosas. Se mencionan también los idiomas que algunos dicen dominar y hay textos escritos en catalán y en inglés, aunque el idioma mayoritariamente empleado es el español.

La segunda agrupación de textos nos llevó a identificar aquellos que describen qué buscan en ese espacio. En un 18\% de la muestra se registraron las menciones que los ADP tienen sobre conocer mujeres en ese espacio. Algunos textos señalan que el motivo es ampliar su red de conocidos y amigos, pero otros específicamente mencionan la expectativa de encontrar pareja, amor o relacionarse sexualmente. En este aspecto es importante señalar que el contenido aquí encontrado se conformó con la identificación de texto que describía sólo lo que se busca en ese espacio, donde aparecen los motivos señalados y, también se mencionan las características de "la mujer" que se está buscando. Esto sin duda captó nuestra atención, ya que como veremos más adelante, la masculinidad también se nutre de la idea de feminidad que se tiene de ella por parte de los mismos hombres (Connell, 2003; Connell y Messerschmidt, 2005), y por tanto, de la mujer que se busca en la RSD Tinder para tener algún tipo de relación.

De lo anterior, se muestra que los textos hacen alusión a describir actitudes y valores de la mujer buscada, entre los que encontramos adjetivos que a continuación se mencionan: "princesa", "abierta", "inteligente", "que piense", "cálida", "cariñosa", "guapa", "buen cuerpo", "amante sexual", "entregada", "comprensiva", "honesta", "viajera", "seria", "arreglada", "que no mienta", "de buen humor", entre otros.

Por último, el tercer grupo de textos que describe qué ofrecen al relacionarse, aquí un 18\% de

Global Media Journal México, 18(34), 229-251, enero - junio 2021. 
la muestra de textos menciona aspectos directos de lo que ellos pueden dar $\mathrm{u}$ ofrecer en el contacto, mencionan aspectos como: "salir a divertirse", "cenar", "bailar", "andar de tapas" (visitar distintos bares en una noche), "viajar", "tener un buen momento sexual", “compañía", "sexo", "relacionarse más allá de salir", "buena conversación", entre otros. También algunos textos citan lo que no ofrecen, señalan directamente que no quieren "compromiso", "relación seria", "relación de pareja", "casarse", entre otros.

Cabe señalar que algunos ADP, no todos, contienen los tres elementos que se han descrito anteriormente, es decir: descripción de sí mismo, lo que busca en ese espacio, y lo que ofrece. A continuación, se muestran tres casos:

1. [Nombre] 41 [edad] Hogeschool West-Brabant [sin información, posible espacio de formación/laboral] ETSEIT UPC [sin información]:

Hola com estàs? Straight sturdy, lush lips, beauty imperfection, seeking nice, smart and cute People around Barcelona.1,88 cm [emoticono con la palabra Top y una flecha hacia arriba] don't ask me in inches lol and 93kg!! So a Big Catalan guy.CAT and ESP, EN and even Dutch spoken. Sporty \& Jaco, wanderlust, I do love to dance, explore, tantra, good vives, adventures and I love to have nice conversation with an impressive person. As a male, I just do not give shi...about socker...I better prefer my hobbies. TOXIC people swipe left!!(ADP_TH_011).
2. [Nombre], 40 [edad] Casa Paco [sin información, posible espacio laboral] ESSCA Ecole de Management [sin información, posible espacio de formación/laboral]. A $2 \mathrm{~km}$ de distancia:

Busco amante regular o rollos [punto y coma con un paréntesis formando una cara con guiño]... Y mas si puede ser!! Llevo tiempo probándolo para amor y me salen ranas, a ver cambiando el enfoque!!! [punto y coma con un paréntesis formando una cara con guiño] Sin pelos en la lengua pero con educación! Y si te gustan y practicas el tenis ylo el golf, mejor todavia!!!! (ADP_TH_015).

3. [Nombre] 38 [edad] A $19 \mathrm{~km}$ de distancia:

Hacer realidad lo que deseamos, sin obligaciones, es el camino! Nuestro mundo está en nuestras manos! ¡Vamos, toca el corazón de Green y déjalo fluir! Aire libre, saco y mochilas, pies de gato y mil sonrisas!! [punto y coma y tres signos de cierre de paréntesis formando una cara sonriente guiñando un ojo] ;La vida se ríe juntos! Y si dejo que me beses pago yo las birras jajajaja. 1,80 cm. Amistad, pasión esporádica o para siempre ... todo dependerá de la complicidad y feeling de ambas partes .... vívela, que la Vida vive en I'ARA!! [palabra sin claro significado]...ABSTENERTE SI ERES EGOCÉNTRICA, PREPOTENTE O 


\section{SOBERBIA! ![Escrito en mayúscula]. [Escrito originalmente en catalán $y$ traducido al idioma español] (ADP_TH_098).}

\section{De los ADP en las imágenes}

En cuanto a las imágenes (fotografías) de los ADP, cabe señalar que el $62 \%$ de la muestra de ADP contiene fotografías sólo de sí mismos, el 36\% son fotografías de sí mismos y otros aspectos, como estar con otra persona (mujer o hombre), o con un grupo de personas (mujeres, hombres, o mixto), con niños o niñas, con animales, con alimentos, con bebidas, con medios de transporte (autos, motocicletas, bicicletas, barcos, avioneta o yate); y el $2 \%$ restante estaba sólo mostrando un paisaje natural.

Además, el $60 \%$ muestra el medio cuerpo superior, el $26 \%$ cuerpo completo, el $12 \%$ sólo rostro y el $2 \%$ sin mostrarse (paisaje natural). En cuanto al espacio, el $66 \%$ ocupa un espacio público, como vías de comunicación, espacios naturales o paisajes y espacios recreativos, bares, restaurantes, tiendas; mientras que el 34\% muestra un espacio privado, como casa/apartamento, jardín, lugar de trabajo.

Posteriormente, el ejercicio de discurso multimodal nos llevó a revisar el contenido global en las imágenes del perfil y los textos de presentación, lo que nos permitió analizar la muestra de ADP y encontrar las autorepresentaciones masculinas y lo emergente en ellas que exponemos a continuación.

\section{La autorepresentación de la masculinidad} basada en el deporte/la fuerza

Este eje es uno de los discursos de mayor presencia en la muestra de ADP, principalmente porque tanto en texto como en imágenes se hace explícita la realización de alguna actividad deportiva, donde se ejecuta algún tipo de actividad que implique la habilidad corporal y fuerza física. Los deportes, tales como box, natación, golf, tenis, maratón, atletismo, bicicleta de montaña, senderismo, o simplemente la actividad en gimnasio, son predominantes en la muestra de imágenes $(n=49)$ que tienen esta representación.

En el caso de las imágenes predominan los perfiles $(n=62)$ que muestran el cuerpo, o parte de él, fortificado, es decir, con figura atlética o muscular, así estén o no haciendo actividad deportiva. En algunos casos $(n=30)$ muestran el cuerpo con músculos (completo o medio cuerpo) y semivestido (en ropa interior o traje de baño).

\section{La autorepresentación de la masculinidad basada en lo material/ la seguridad}

En esta representación se puede observar que los ADP muestran abiertamente sus posesiones materiales, desde vivienda, ropa y/o medios propios de transporte, hasta la capacidad económica para proponer invitaciones a bares, restaurantes, viajes, y actividades deportivas, entre otras. Además, algunos ADP señalan su formación académica y/o su espacio laboral o definiciones personales de seguridad, como señalar que son independientes, trabajadores, 
dedicados, directos, y con control para tomar decisiones. Encontramos que 75 perfiles de la muestra de imágenes se representan con elementos de estabilidad económica (objetos propios, casa, viajes, trabajo, entre otras).

En el aspecto de seguridad en la interacción social (amigos, personas, hijas/os), en las imágenes $(n=16)$ se observa este aspecto, y en los textos se menciona recurrentemente el gusto por la interacción social. En cuanto al espacio público, en la muestra de imágenes que hace uso de él $(n=80)$, pudimos encontrar que dentro de este conjunto, el $53 \%$ se muestra en paisajes naturales (playas, bosques o montañas), el $28 \%$ en vías de comunicación (calles, avenidas o autopistas) y $19 \%$ en espacios recreativos.

\section{La autorepresentación de la masculinidad basada en la aventura/la osadía}

En este caso, la muestra nos permite obtener un discurso textual-visual sobre ADP de hombres que gustan de la aventura- literalmente señalada en los textos de presentación-, viajando o practicando alguna actividad extrema. Varios ADP mencionan que les gusta viajar a lugares desconocidos, silvestres, salvajes o saltar del paracaídas. Además, el 60\% $(n=72)$ de las imágenes muestran a los sujetos con base en aquellas representaciones, es decir, con acciones como las de estar escalando, volando, acampando, haciendo deporte o deporte extremo, entre otras.

En algunos casos, el $11.6 \%(n=14)$ de los ADP representa una masculinidad más osada como las de presentarse a lado de animales salvajes y no domesticables, como con leones o serpientes.

\section{La autorepresentación de la masculinidad basada en el romance/apertura sexual}

Para esta representación se destaca los ADP que textual y/o visualmente presentan discursos románticos, ya sea que usen el término para describirse o para describir la relación que están buscando. Del 18\% de ADP $(n=22)$ podemos decir que 12 recurren a elementos lingüísticos utilizando poesía o citando alguna novela o película romántica en sus textos de presentación y 10 expresan que les importa el romance, que buscan momentos donde puedan recibir cariño o encontrar pareja o compañía sexual. En cuanto a imágenes, $22.5 \%(n=27)$ se muestra en alguna situación relajada, íntima -con velas, vino, el atardecer, entre otras-. También se encuentran ADP que aluden a que ofrecen relaciones sin compromiso, a relaciones abiertas sexualmente, $\mathrm{o}$ a las que son extramaritales.

\section{La representación de la mujer desde las autorepresentaciones masculinas}

Uno de los elementos que puede observarse principalmente en lo textual y no recurrentemente en las imágenes -aunque sí está presente-, es la descripción que los ADP hacen de la mujer heterosexual- que esperan encontrar, así como también algunos adjetivos asociados a la feminidad, como en el caso en que ellos dicen que buscan comprensión, amabilidad, cariño, escucha, 
delicadeza, bondad, etc. De manera mayoritaria, los $\operatorname{ADP}(n=27)$ que citan este tipo de texto en la muestra nos deja ver el contenido del uso de adjetivos que describen a la mujer y alguna característica de su actuar. Mostramos algunos ejemplos para clarificar más esta representación:

- "Solo chicas con cerebro porfi" (ADP_TH_019)

- "Las chicas normales me aburren, las raras me asustan, ¿algún termino medio?’ (ADP_TH_032)

- "Buscando a una chica interesante, aunque sea difícil..."(ADP_TH_073)

- "Ni Casadas -Ni Salidas -Besadoras de perros tampoco" (ADP_TH_079)

- “...me gustaría encontrar a una chica que me atraiga..."(ADP_TH_097)

- “...ABSTENERTE SI ERES EGOCÉNTRICA, PREPOTENTE O SOBERBIA! [Escrito en mayúscula y originalmente en catalán]" (ADP_TH_098)

- “Aprecio más la capacidad de sentir que el intelecto, a la vez que necesito una comunicación inteligente. Con ganas de pasar buenos ratos, sin compromisos ni ataduras..." (ADP_TH_001).

- "El físico atrae.... La inteligencia seduce...... Y la bondad enamora" (ADP_TH_025)

- “En busca de mi princesa..." (ADP_TH_099)

${ }^{1}$ Se optó por presentar este trabajo con la descripción textual de las imágenes a las que nos referimos y que forman parte de muestra, así como de la base de datos del presente estudio. Lo anterior no afecta de ninguna forma el contenido, resultados o análisis aquí presentados, al
Como ejemplos de las imágenes ${ }^{1}$ tenemos los siguientes casos:

1. Fotografía que muestra el cuerpo completo de un hombre que está sentado en un sillón, viste una playera de color negro de cuello redondo y pantalón azul; en la muñeca izquierda trae un reloj de color negro y en la muñeca derecha, trae una pulsera y un objeto que parece un guante incompleto. Con ambas manos sujeta una cámara con la que parece estar tomado una fotografía a una mujer de la que sólo se ve el medio cuerpo superior, recostada boca abajo en un sillón de dos piezas de color blanco. La mujer está semivestida, sólo con ropa interior de color negro, es de tez morena y su cabello es largo y semiondulado; al lado de su brazo derecho hay un antifaz de color negro, su brazo izquierdo está doblado y con su mano sujeta una parte de su cabello y su brazo derecho también doblado y recargado sobre el sillón, pareciera estar posando para la fotografía y viendo fijamente a la cámara. El piso es de color negro y detrás de los sillones se ve una mesa y dos sillas en color café, en la pared hay un espejo con un marco negro, al parecer hay un ligero espacio enfrente del espejo en donde está colocada una lámpara. El escenario es un espacio

contrario, la descripción realizada es lo que nos permite presentar el análisis y la discusión efectuada. Las negritas son para resaltar aspectos relevantes de la descripción. 
privado e iluminado $[\mathrm{El}$ ADP no indica alguna información sobre actividad laboral, profesional o alguna otra relacionada con el movimiento de la imagen] (ADP_TH_078).

2. Hay dos fotografías montadas sobre una misma imagen de perfil: en la primera se muestra el cuerpo completo de una mujer blanca de cabello obscuro y ojos rasgados, con cara a media sonrisa que lleva puesto un vestido de novia blanco, con el brazo izquierdo está cargando una bolsa blanca y en la mano tiene un guante también del mismo color del vestido. La mujer sostiene un arma (pistola) con la que se apunta hacia la sien; se muestra sonriente, en su cuello tiene un collar plateado. Detrás de ella se ve un mueble, a su costado izquierdo hay otro mueble de metal, una parte del piso es liso y la otra tiene cuadros pequeños; el mueble que está detrás de ella tiene cristales por los cuales se ven varios objetos que parecen cajas y encima de ese mueble hay otros objetos que no se distinguen bien. En la segunda fotografía se ve el medio cuerpo superior de una mujer sin poder observarse la totalidad de la cabeza sólo que tiene cabello rubio, ella viste una playera corta sin mangas de color azul claro y un atuendo de mezclilla que queda cortado en la imagen.

\section{La playera tiene una frase en color negro} que dice "I WISH THESE WERE $\boldsymbol{B R} \boldsymbol{A I N S}$ " -el texto está en mayúsculas y en español se traduce literalmente "desearía que estos fueran cerebros"-, la frase se encuentra justo la altura donde se observan los senos de esta mujer. Detrás de ella hay una estructura verde (ADP_TH_079).

3. En la fotografía se muestra un grupo de tres hombres, de los cuales sólo a uno se le observa la cara completa. Se encuentra al frente y del lado izquierdo. Viste un saco color gris y una camisa blanca con dos franjas negras, en el cuello trae un collar, en su nariz tiene puesta una nariz de goma color rojo, similar a la que usan los payasos. Es de tez blanca, ojos de color marrón y calvo. El sujeto se muestra sonriente y sostiene una muñeca de plástico, de color rosa, con cabello amarillo, maquillada $y$ con la boca abierta, semejante a las que se utilizan para actividades sexuales, la muñeca ocupa la parte media de la fotografía, los otros hombres también la están sosteniendo. Los otros dos hombres no se distinguen claramente; uno de ellos en la parte media alta de la fotografía muestra algunas partes de sus brazos y manos y la mitad de su cabeza (nariz y boca), viste un saco color azul con una camisa blanca, usa barba y bigote y se encuentra mostrando su lengua. Junto a ellos, del lado derecho, está un hombre que muestra sólo su hombro y su cabeza no se ve completa sólo la mitad; se muestra sonriente y usa barba y bigote, viste 
una camisa de color como gris con figuras que no se distinguen. De tras de ellos de lado derecho se ve un árbol adornado con una tira de lámparas pequeñas, y de lado izquierdo, pero en un plano más alejado, se ve una persona sentada. Se observa que el escenario es un espacio público, puede ser un jardín y con luz de día (ADP_TH_016).

A partir de los ejemplos podemos señalar que si bien las expectativas del espacio digital son generar un puente de atracción de las personas desde lo visual, el contenido producido por la autorepresentación masculina en distintos ADP en Tinder nos muestra que la idea de mujer o feminidad se inscribe en encontrar una mujer con afinidad heterosexual y con normativas de lo que se esperan de ésta. En ese sentido, las frases que utilizan para describirlas transmiten mensajes de cómo quieren que sea una mujer: "inteligente", "con cerebro", "interesante", "no normal-aburrida", "no rara", entre otras, como si esas cualidades que citan fueran algo especial, extraordinario o difícil de encontrar en una mujer y, por ende, parece que se presupone que el antónimo de lo que citan es lo común a las mujeres. También indican que no sean "egocéntricas", "prepotentes", "soberbias", que en este caso dichos rasgos podrían entrar en conflicto con el mandato social pasivo, dependiente, receptivo, de cuidados o sumisión que se le atribuye a la categoría mujer.

A pesar de ello, también las definen como "princesa", situándose ellos como "príncipes"; y especialmente en diversas imágenes, como algunas descritas anteriormente, se configura una imagen de mujer como cuerpo, como objeto sensual y sexualizado, destinado a la recreación de los hombres. Por otro lado, la idea de "sujeción" representada por la expresión "sin compromiso o ataduras", o bien la imagen de "novia apuntando a su propia sien", cobran un significado de que ciertas situaciones y relaciones con las mujeres no tienen que consistir en "compromiso", "matrimonio", "ataduras", etc. Especialmente porque eso en discurso y creencia constituye pérdida de autonomía o sujeción hacia lo femenino, por lo que es necesario distanciarse.

Como puede observarse, la mujer se encuentra conceptualizada de forma muy apegada al estereotipo de feminidad: no interesante, no inteligente o que debe serlo y/o receptora $y$ respondiente a las necesidades masculinas (físicas, afectivas y/o sexuales), incluyendo el tipo de relación que deben esperar (Butler, 2001; Osborne, 1995).

Por último, cabe señalar que dentro de la muestra de 120 ADP, sólo dos perfiles estarían identificados sin una ligazón directa con alguna de las autorepresentaciones masculinas mencionadas, fundamentalmente porque no se describen a sí mismos, no definen lo que buscan, y en particular, uno ofrece un espacio para conocer personas y el otro utiliza alguna frase que no tiene una explicación literal. Presentamos los casos:

1. Nombre], 43 [edad] Cultura Practica [sin información] A $2 \mathrm{~km}$ de distancia:

Buscando conocer gente para salir a tomar algo, charlar y compartir aficiones. Me 
gustan tantas cosas que mejor las van descubriendo. No abdominales. No sport héroe. Un perro y una hija [emoticono de cara sonriente].

[En la fotografía se ve el medio cuerpo superior de un hombre que se encuentra sentado, probablemente en un restaurant/terraza y que viste una playera de color rojo y carga un morral color verde; delante de él hay un objeto de alfarería que podría ser una jarra o un tarro con alguna bebida. Detrás de él hay unas mesas con sus sillas y al fondo se ven muros de cristal. El hombre se muestra con una ligera sonrisa y no se ven los ojos porque están cortados en la imagen. La fotografía está tomada por otra persona, en un espacio público y con luz de día] (ADP_TH_080).

2. [Nombre], 36 [edad] A $19 \mathrm{~km}$ de distancia:

A veces, nuestros sueños grandes, están hechos de cosas muy pequeñas.

[En la fotografía se observa una mano sosteniendo una copa de vino blanco, de frente a esa copa se ve mucho pasto verde y algunas colinas que se iluminan con la luz del sol. Es un espacio abierto. La imagen muestra el amanecer o atardecer] (ADP_TH_107).
En estos dos ejemplos, las fotografías no muestran claramente alguna representación y, en uno de los casos, se muestra un objeto y paisaje. Es posible que ello tenga que ver con una dinámica expectante explorador/observador- del espacio propiciado por la RSD y lo que se produce en él, para involucrarse en las interacciones en Tinder. Estos hombres se definen como "algo para ir descubriendo", o "en las pequeñas cosas", o bien como "con un perro y una hija" que pudiera indicar un rol diferente, lo cual se interpreta como la apertura de un marco relacional en el que lo que se es, se ofrece o se busca estará en la interacción subsecuente, y ello podría ser un indicio de entender la masculinidad desde otras posiciones.

En términos de los resultados globales obtenidos y conforme a lo planteado por autores como Bonino (2002) y Kimmel (Carabi y Armengol, 2008), identificamos que la autorepresentación digital de la masculinidad en Tinder tiene claramente la configuración simbólica de la masculinidad hegemónica dominante. En primer lugar porque las estrategias de autoafirmación masculina, que caracterizan a los hombres como seguros, fuertes, estables y en constante verificación de su masculinidad, se ligan con las autorepresentaciones digitales de la masculinidad basada en el deporte/la fuerza, lo material/seguridad y en la aventura/la osadía; pues en estas tres representaciones los ADP muestran preocupación por cómo luce el cuerpo (controlado y fuerte) y la persona como tal (con seguridad y con capacidad material y económica). Además de que en estas tres representaciones también están ligadas a creencias que se manifiestan en los ADP, como por ejemplo, la autosuficiencia 
prestigiosa, en aquellos que muestran concepciones positivas de sí mismos, tales como ser trabajadores e independientes; la belicosidad heroica, donde mostrarse como deportista o en actividades extremas forman parte de una constante en los resultados encontrados; o el respeto al valor de la jerarquía, que se describe cuando se mencionan las capacidades, las profesiones, o lugares de trabajo, colocándose como sujetos aptos en la autonomía para la toma de decisiones o motivaciones propias.

Los aspectos materiales que muestran los ADP, se conjugan con el estereotipo de hombre blanco, heterosexual y con un estatus económico que le da movilidad en la esfera pública/económica/sexual, basada en los preceptos de la masculinidad hegemónica. Es aquí donde la interseccionalidad tiene presencia, es decir, que dicha hegemonía define y fortalece la heterosexualidad con dos ejes de privilegio, como son el estatus económico alto y el ser adulto blanco.

En el caso de las autorepresentaciones digitales de la masculinidad basadas en el romance/apertura sexual vemos que hay dos grupos de componentes opuestos constantes en la muestra. Por un lado, la relación de pareja versus sexo casual $\mathrm{y}$, por otro, el compromiso y seguridad de una relación estable versus no compromisos/ataduras. Esto se conjuga desde la representación de la mujer desde las autorepresentaciones masculinas, ya que hay un componente textual y visual que recurre a la estrategia de la huida -de la mujer- en el sentido de aclarar el no compromiso o la atadura, o incluso cuando se presentan calificativos hacia las mujeres que no desean conocer (egocéntricas, prepotentes, deshonestas, entre otras).

Por otra parte, el que los ADP se muestren como heterosexuales y lo reiteran en su descripción o en las imágenes, hace predominante que los componentes de la masculinidad hegemónica aparezcan como la tendencia de los hombres de saberse favorecidos, tanto de la desigualdad existente para y hacia las mujeres, como de su definición binaria estereotipada de la feminidad -tradicional o no- que continúa participando en una relación de desigualdad. Por ejemplo, cuando se reitera que buscan que sean inteligentes/que piensen y que es difícil encontrar esa cualidad, se conecta con la idea estereotípica de que no es común que las mujeres lo sean; o cuando mencionan que buscan que sean guapas/atractivas se presenta otro estereotipo ligado a canon de belleza idealizado de hombre/mujer heterosexual occidental.

Además, lo encontrado en los ADP también indica lo que Illouz (2009) denomina la intersección del tecnocapitalismo y la mercantilización del romance. Esto es, relaciones entre personas y/o de pareja condicionadas por necesidades masculinas, lo cual simula el vínculo cliente-producto-compra, es decir, una cultura de masas del romance que se mueve bajo la dinámica del consumo de productos, incluyendo las ideas tradicionales del amor romántico o del sexo casual y superfluo; discursos que son la base del espacio de interacción social en la RSD Tinder (David y Cambre, 2016).

En cuanto a los modelos de masculinidades alternativos (Carabí y Armengol, 2014; Connell, 2003), si bien identificamos que en la muestra 
trabajada hay algunos $\mathrm{ADP}(n=2)$ que no establecen alguna conexión directa con las autorepresentaciones masculinas, tampoco hay indicios claros de que forman parte de nuevos modelos masculinos. Por lo encontrado en el presente trabajo, no descartamos que las formas alternativas o positivas (Espinar y Ocampo, 2017a, 2007b) en la RSD Tinder, podrían visualizarse de forma muy sutil, por ejemplo, entre perfiles que utilizan recursos lingüísticos de emparejamiento asertivos, que no descalifican/respetan, pero que en sus imágenes (fotografías), o en alguna otra parte del texto de presentación, revelan algunos aspectos ligados a la masculinidad dominante. Lo que sí puede observarse en esos ADP es la inercia de continuar manteniendo una autoafirmación de la masculinidad en términos de las creencias matrices (Bonino, 2002), sin cuestionar el estereotipo masculino-femenino creador de desigualdades y violencia.

No hay duda de que la vida social actual se mueve bajo la dinámica de la cultura digital, donde también está presente la normatividad de género dominante de la cultura moderna occidental. Es importante señalar que el propio marco de comunicación en Tinder modela las relaciones, es decir, la propia RSD es una tecnología de poder como productora y reproductora de relaciones de género normativas y binarias (Butler, 2001) y, dado que Tinder es una ventana al mundo donde muchos y muchas encuentran esos modelos escenificados de forma gráfica y visual, se produce un efecto de sobrereproducción digital del modelo dominante del que es difícil substraerse.

\section{Conclusiones}

En este trabajo se han explorado los objetivos propuestos al inicio; por un lado, conocer cómo los hombres configuran y autorepresentan su masculinidad en la RSD Tinder y qué características son emergentes en relación con ella. A la vez, visualizar cómo se manifiesta la masculinidad dominante dentro del repertorio de masculinidades que se presentan. Por otro lado, comprender cómo esta representación se relaciona con el sistema sexogénero binario, especialmente, cómo define la representación tipológica de mujer y rasgos de feminidad que se conjugan con la masculinidad dominante, y qué efectos adquiere al ser representada en Tinder. El análisis nos ha permitido interpretar texto e imagen de forma independiente $\mathrm{y}$, a la vez, interconectada (multimodal), pudiendo identificar la significación de aspectos relevantes de la configuración de la masculinidad dominante performada como acto comunicativo en los ADP.

A partir de textos e imágenes de Tinder, mostramos cómo los hombres heterosexuales se autorepresentan con descripciones de sí mismos, de lo que buscan en ese espacio, y lo que ofrecen, utilizando características emergentes de una masculinidad hegemónica (Bonino, 2002; Carabí y Armengol, 2014; Connell, 2003). Encontramos formas de autoafirmación de esta masculinidad a través de sus expresiones y de sus imágenes, que hemos catalogado como autorepresentación de la masculinidad basada en el deporte/la fuerza; en lo 
material/ la seguridad; en la aventura/la osadía; y en el romance/apertura sexual.

Los ADP se caracterizan por ofrecer una masculinidad donde el régimen heterosexual- basado en el binarismo de género y el modelo hegemónicoademás de sobrerepresentarse, se emplea como estrategia masculina para "despertar el deseo" y/o "ser deseado".

Hay pocos indicios de encontrar otras masculinidades alternativas. Estas últimas, si lo llegaran a ser, quizá todavía sean precarias e incipientes. Lo que hemos encontrado, nos está indicando ciertas direcciones hacia donde apunta la misma masculinidad como cuando los hombres se colocan en posiciones expectantes hacia las relaciones de pareja; o como cuando ellos mismos hacen referencia a un futuro relacional por explorar, sin autoafirmarse entre los rasgos estereotípicos; o como cuando adoptan roles más de cuidado y no tan individuales. En estos elementos de inflexión puede entreverse algún amago de interpelar a la masculinidad dominante. Sin embargo, el contexto virtual Tinder, como marco interpretativo donde se dan esas interacciones, está predefinido en cuanto a cómo debemos concebir el sistema sexo-género. También, en cuanto a qué esperamos, qué buscamos de la construcción del amor, de las relaciones sexuales, del gozo, etcétera (Butler, 2007). Ese espacio digital de igual manera nos presenta cómo estamos contenidos en una sociedad estructurada, con una ordenación de género predefinida, a partir de la cual nos socializamos hombres y mujeres. Tinder actúa como una tecnología de poder (Foucault, 1978) en el sentido que se construye como un escenario específico que produce efectos de producción y reproducción ampliada y extensa de las categorías creadas en torno a los géneros, que hace que la masculinidad se mueva en dos esferas íntimamente conectadas: el mantenimiento conservador de las relaciones de género y el favorecimiento de la sociedad de consumo (Hearn, 2017; Illouz, 2009).

Por tanto, nos preguntamos si Tinder como red de relaciones sociales puede introducir fisuras en las concepciones dominantes de la masculinidad, concretamente si permite mostrar en el espacio público de la red pequeñas acciones que comporten cuestionar el sistema heteropatriarcal, en especial, a partir de formas de ruptura con los estereotipos.

Nuestros resultados apuntan a que no hay rupturas con esas concepciones o modelos, ni con ese sistema, sino que, además, la construcción de la masculinidad-feminidad convive en un equilibrio de fuerzas en Tinder, que permiten mantener el sistema de jerarquías y desigualdades. Es decir, en ese espacio se refuerza, se acentúa, y se hace más extensiva la categoría y estereotipo de masculinidad hegemónica, y, por ende, de feminidad. Ambas se retroalimentan continuamente con efecto de mantener el orden heteropatriarcal (Bard y Magallanes, 2018).

No obstante, como limitaciones de este trabajo, consideramos lo apremiante que es abrir espacios para explorar y analizar a los sujetos que participan en Tinder a través de otras técnicas cualitativas, como lo puede ser con entrevistas o narrativas, que nos permitan recoger las experiencias a partir de la red y de los contactos realizados. Estos sujetos no tienen que ser sólo los hombres, sino 
también estudiar la interacción y la subjetividad que se establece con las mujeres. Además, apuntamos también el papel y concepción de la sexualidad dentro de los encuentros en la red como un elemento clave para entender el modelo hegemónico de masculinidad y sus efectos. Consideramos que es importante analizar con mayor profundidad la masculinidad en Tinder en relación con otras intersecciones. Si bien nuestros resultados sugieren que la masculinidad heterosexual parte de variables como el estatus socioeconómico, los cánones de la figura corporal fuerte y vigorosa y el ser adulto blanco (europeo/español/catalán), entendemos que ahondar en el análisis de la masculinidad también precisa una mayor exploración de otras variables como clase, raza y orientaciones no heterosexuales, así como de otros elementos que pueden estar presentes. Además, se requiere contemplar los estereotipos asociados a la masculinidad, feminidad y sexualidad que, desde el entorno digital y la lógica algorítmica de similitud para conectar a las personas usuarias (MacLeod y McArthur, 2017), podrían estar enfatizando una configuración mediática determinada del género en la construcción de los ADP y sus interacciones.

\section{Referencias bibliográficas}

Ardèvol, E. y Muntañola (2004). Visualidad y mirada. El análisis cultural de la imagen. En E. Ardèvol y N. Muntañola, (Coord). Representación y cultura audiovisual en la sociedad contemporánea. (pp. 17-46). Editorial UOC.

Bard G. y Magallanes, M. (2018). El masculinismo hetero-hegemónico argentino y su estrategia desde el ciberactivismo. Masculinidades y cambio social, 7(1), 25-51. http://doi.org/10.17583/MCS.2018.2827

Bard, G. y Magallanes, M. (2021). Instagram: La búsqueda de la felicidad desde la autopromoción de la imagen. Culturales, 9, e519. https://bit.ly/3x4W5pp

Barrionuevo, L. y Torrano, M. (2018) Las subjetividades del control: entre la precariedad y la servidumbre maquínica. Revista Barda; 6, 36-50. https://bit.ly/3uW0OZ5

Bauman, Z. (2005). Amor líquido, acerca de la fragilidad de los vínculos humanos. Fondo de Cultura Económica.

Bonino, L. (2002). Masculinidad hegemónica e identidad masculina. Dossiers feministes, 6, 7-36. https://bit.ly/3g5mqx4

Butler, J. (1988). Performative acts and gender constitution: an essay in phenomenology and feminist theory. Theatre Journal, 40(4), 519-531. https://doi.org/10.2307/3207893

Butler, J. (2001). Mecanismos psíquicos del poder: Teorías sobre la sujeción. Cátedra.

Butler, J. (2007). El género en disputa. El feminismo y la subversión de la identidad. Paidós

Caballero, A. A. y Herrero-Jiménez, B. (2017). Representaciones de género en las redes móviles de contactos cuerpo e identidad en «adopta un tío». Prisma Social, 2, 31-56. https://bit.ly/3fYjKkL

Global Media Journal México, 18(34), 229-251, enero - junio 2021. 
Calvo González, S., Gómez-Beltrán, I. y Fernández-Fernández, D. (2020). Expresiones de cuerpos diversos en espacios de encuentro digitales. Diversidade $\quad E \quad$ Educação, 8, 42-69. https://doi.org/10.14295/de.v8iEspeciam.9710

Carabí, À. y Armengol, J. M. (2008). La masculinidad a debate. Icaria.

Carabí, À. y Armengol, J. M. (2014). Alternative masculinities for a changing world. Palgrave Macmillan.

Casimiro, C. (2014). Portuguese online dating: exploring gender differences in self-presentations. Teknokultura. Revista De Cultura Digital Y Movimientos Sociales, 11(1), 117-141. https://bit.ly/3uDZY3k

Castells, M. (2010). The rise of the network society. Wiley-Blackwell.

Connell, R. W. (2003). Masculinidades. Universidad Nacional Autónoma de México. Programa universitario de Estudios de Género.

Connell, R. W. (2012). Masculinity research and global change. Masculinities \& Social Change, 1(1), 4-18. https:/hipatiapress.com/hpjournals/index.php/mcs/article/view/157/89

Connell, R. W. y Messerschmidt, J. W. (2005). Hegemonic masculinity: rethinking the concept. Gender \& Society, 19(6), 829-859. https://doi.org/10.1177/0891243205278639

David, G. y Cambre, C. (2016). Screened intimacies: Tinder and the swipe logic. Social Media + Society, 2(2), 111. https://doi.org/10.1177/2056305116641976

Espinar-Ruiz, E. y Ocampo, I. (2017a). La representación de masculinidades en las páginas web de citas. Prisma Social, (18), 561-570. https://bit.ly/3yR4WNi

Espinar-Ruiz, E. y Ocampo, I. (2017b). Ways of masculinity in online dating profiles: the cases of Meetic.es and AdoptaUnTio.es. Masculinities and Social Change, 6(3), 196-216. http://doi.org/10.17583/MCS.2017.2709

Forceville, C. J. (2011). Multimodality: a social semiotic approach to contemporary communication. Journal of Pragmatics, 43(14), 3624-3626. https://doi.org/10.1016/j.pragma.2011.06.013

Foucault, M. (1978). Microfisica del poder. La Piqueta

Giddens, A. (1998). La transformación de la intimidad. Cátedra.

Gil Calvo, E. (2005). Máscaras masculinas: Héroes, patriarcas y monstruos. Anagrama.

Gilmore, D. D. (1994). Hacerse hombre: concepciones culturales de la masculinidad. Paidós.

Halberstam, J. (2012). Gaga feminism: sex, gender, and the end of normal. Beacon Press.

Haraway, D. J. (1991). Manifiesto cyborg. Ciencia, tecnología y feminismo socialista finales del siglo XX. Cátedra. Hearn, J. (2017). Two challenges for critical studies on men and masculinities: the hegemony of men, and trans(national)patriarchies. Casopis za Kritiko Znanosti: Domisljijo in Novo Antropologijo (267), 23-34. https://bit.ly/3icze $7 \mathrm{~h}$

Hine, C. (2014) Etnografia virtual. Editorial UOC.

Illouz, E. (2009). El consumo de la utopía romántica: el amor y las contradicciones culturales del capitalismo. Katz Editores.

Global Media Journal México, 18(34), 229-251, enero - junio 2021. 
Kimmel, M. (1996). Manhood in America: a cultural history. Free Press.

Kimmel, M. (2007). The gendered society. Oxford University Press.

Kress, G. R. (2010). Multimodality: a social semiotic approach to contemporary communication. Routledge.

MacLeod, C. y McArthur, V. (2018). The construction of gender in dating apps: an interface analysis of Tinder and Bumble. Feminist Media Studies, 19(6), 822-840. https://doi.org/10.1080/14680777.2018.1494618

Martínez-Lirola, M. (2012). Aproximación a la interacción virtual: el caso de la red social Badoo. Palabra Clave, 15(1), 107-127. https://bit.ly/34Fb5hy

Martínez-Salgado, C. (2012). El muestreo en investigación cualitativa: principios básicos y algunas controversias. Ciência \& Saúde Coletiva, 17(3), 613-619. https://doi.org/10.1590/S141381232012000300006

Miller, H. (1995). The presentation of self in electronic life: Goffman on the internet. University of London. Embodied Knowledge and Virtual Space Conference Goldsmiths. https://bit.ly/3c9Qarb

Niklander, S., Soto, R. y Crawford, B. (2015). Female gender representations in digital mass media via discourse analysis: a case study. 10th Iberian Conference on Information Systems and Technologies (CISTI), 1-6. https://doi.org/10.1109/CISTI.2015.7170610

O’Halloran, K. L. (2012). Análisis del discurso multimodal. Revista Latinoamericana de Estudios del Discurso, 12(1), 75-97. https://bit.ly/3c6bldC

Osborne, R. (1995). Sexo, género, sexualidad. La pertinencia de un enfoque constructivista. Papers: Revista de Sociología, (45), 25-31. https://bit.ly/3wLMOm1

Pink, S. (2010). Interdisciplinary agendas in visual research: re-situating visual anthropology. Visual Studies, 18(2), 179-192. https://doi.org/10.1080/14725860310001632029

Pink, S., Horst, H., Postill, J., Hjorth, L., Lewis, T. y Tacchi, J. (2019). Etnografía digital. Principios y práctica. Morata.

Platero, L. (2012). Intersecciones: cuerpos y sexualidades en la encrucijada. Bellaterra.

Poster, M. (2002). Everyday (virtual) life. New Literary History, 33(4), 743-760. https://bit.ly/34BY60o

Ranzini, G. y Lutz, C. (2017). Love at first swipe? Explaining Tinder self-presentation and motives. Mobile Media \& Communication, 5(1), 80-101. https://doi.org/10.1177/2050157916664559

Reavey, P. (2012). The return to experience: psychology and the visual. En P. Reavey (Ed.), Visual methods in psychology. Using and interpreting images in qualitative research (pp. 1-13). Routledge.

Reavey, P. y Johnson, K. (2008). Visual approaches: using and interpreting images. En C. Willig y W. StaintonRogers (Eds.), The SAGE handbook of qualitative research in psychology (pp. 296-314). Sage.

Rubin, G. (1986). El tráfico de mujeres: notas sobre la economía política del sexo. Revista Nueva Antropología, 30(3), 95-145. https://bit.ly/2RSQ8NK

Global Media Journal México, 18(34), 229-251, enero - junio 2021. 
Segato, R. L. (2003). Las estructuras elementales de la violencia: ensayos sobre género entre la antropología, el psicoanálisis y los derechos humanos. Universidad Nacional de Quilmes-Prometeo.

Serrano-Puche, J. (2015). Emociones en el uso de la tecnología: un análisis de las investigaciones sobre teléfonos móviles. Observatorio (OBS*), 9(4). https://bit.ly/3g1MM2K

Torrano, A. (2019). "Habitamos una época marcada por un doble proceso de tecnificación y politización de la vida" entrevista a Flavia Costa. Heterotopias, 2(3). https://bit.ly/3gfO6PO

Van Dijk, T. A. (2019). El discurso como interacción social. Gedisa

Van Leeuwen, T. (2008). Discourse and practice: New tools for critical discourse analysis. Oxford University Press.

Van Leeuwen, T. y Jewitt C. (2004). The handbook of visual analysis visual meaning: a social semiotic approach. SAGE Research Methods, 29. https://doi.org/10.4135/9780857020062

West, C. y Zimmerman, D. H. (2009). Accounting for doing gender. Gender \& Society, 23(1), 112-122 https://doi.org/10.1177/0891243208326529

Global Media Journal México, 18(34), 229-251, enero - junio 2021. 